\title{
Changes in fibrolytic microbes and enzymes of fistulated goat in response to feeding with methanol extract of Sapindus rarak
}

\author{
E. Wina ${ }^{2}$, S. Muetzel ${ }^{1}$, E. Hoffmann ${ }^{1}$ and K. Becker ${ }^{1,3}$ \\ ${ }^{1}$ Institute for Animal Production in Tropics and Subtropics (480b), University of Hohenheim \\ Stuttgart 50793, Germany \\ ${ }^{2}$ Indonesian Research Institute for Animal Production \\ P.O. Box 221 Bogor 16002, Indonesia
}

\begin{abstract}
Saponin containing methanol extract of Sapindus rarak (MS) was fed to four fistulated goats to study its effect on major fibrolytic microbes and fibrolytic enzyme activity. Rumen liquor was taken at pre-, during and post MS feeding. Fibrolytic microbes except Fibrobacter dropped dramatically at 3 days of feeding and regained its concentration at 6 days post feeding. A reduction of xylanase and CMCase activities only occurred after 3 days of MS feeding. No correlation was found between the concentration of these microbes to the xylanase or CMCase activities in the rumen.
\end{abstract}

KEY WORDS: Sapindus rarak, goat, fibrolytic microbes, xylanase, CMCase

\section{INTRODUCTION}

Previous in vitro works showed that Sapindus rarak fruit and its methanol extract which contained saponins reduced protozoal count, eukaryotes concentration (Wina et al., 2003) and xylanase activity which resulted in a decrease of digestibility (Wina, in preparation). Using Rusitec system, Hess et al. (2003) found that S.saponaria reduced protozoa but not the OM digestibility. Limited information has been reported on the in vivo effect of Sapindus feeding on major fibrolytic microbes and fibrolytic enzyme activity. Thalib et al. (1997) showed an increase in total cellulolytic bacteria and total tract digestibility which were in contrast to the in vitro results. Therefore, it is important to investigate the

\footnotetext{
${ }^{*}$ Supported by PAATP, Ministry of Agriculture, Indonesia

${ }^{3}$ Corresponding author: e-mail: kbecker@uni-hohenheim.de
} 
effect of Sapindus saponins on major fibrolytic microbes and its relation to their enzyme activity in goat.

\section{MATERIAL AND METHODS}

Methanol extract of Sapindus rarak fruits, MS was prepared by soaking the dried powder pericarps (bought from Central Java, Indonesia) in methanol overnight. The extract was evaporated and freeze dried. The dried product would be used for feeding experiment. MS was incorporated in wheat pollard and fed twice a day at the level of $0.06 \%$ of BW/day to 4 fistulated goats (BW $31.9 \pm 7.9 \mathrm{~kg}$ ). Sugarcane tops were used as roughage. The goats have previously been exposed to MS but the previous MS feeding has been stopped more than 6 days before this experiment started. Rumen liquor was taken before morning meal at pre, during and post MS feeding $(-6,-3,0,1,3,6,+3,+6$ days $)$ for RNA and enzyme activities. RNA was extracted in phenol chloroform and used to study the structure of microbial community using isotopic labelled $\left({ }^{32} \mathrm{P}\right)$ probe oligonucleotide targeting $16 \mathrm{~S}$ rRNA which were used for Fibrobacter, Ruminococcus albus, Ruminococcus flavus and Chytridiomycetes (fungi). Xylanase and CMCase activities were measured (Muetzel et al., 2003).

\section{RESULTS}

The major fibrolytic microbes showed different responses to MS feeding although there were a high variation among animals (Figure 1A,B,C). Fibrobacter remained unchanged and about $0.94 \%$ to the total bacteria concentration. A decrease of concentration of Ruminococcus (R.. albus, $R$. flavefaciens) and fungi occurred after 3 days of MS feeding. Both Ruminococcus and fungi concentrations remained very low (below detection limit) and a quick increase of concentration at 6 days post feeding.

Xylanase activity showed a reduction during MS feeding but a large variation among animals was found (Figure 1D). CMCase acitivity only slightly declined (data not shown). Both enzymes regained their activities soon at post feeding.

\section{DISCUSSION}

Fibrobacter are gram negative while Ruminococcus are gram positive bacteria which were negatively affected by MS feeding. Wang et al. (2000) previously reported that in cell culture, saponins from $Y$. schidigera inhibited the growth of $R$. albus and $R$. flavaciens and fungi while Fibrobacter was the most resistant one. Gram negative bacteria possess two membranes in their cell walls, those are the outer membrane and the additional lipo polysaccharides - protein. These membranes perhaps protect the Gram negative bacteria from the saponins in MS. 
A. Fibrobacter, $\mu \mathrm{g} / \mathrm{ml}$

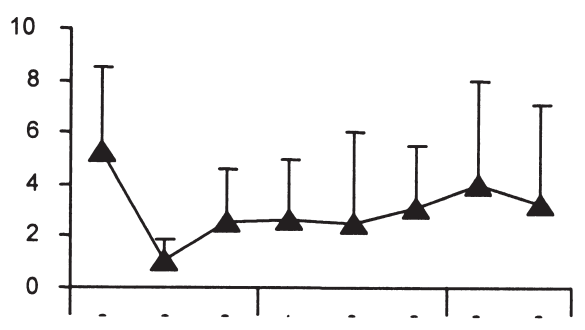

C. Chytridiomycetes, $\mu \mathrm{g} / \mathrm{ml}$

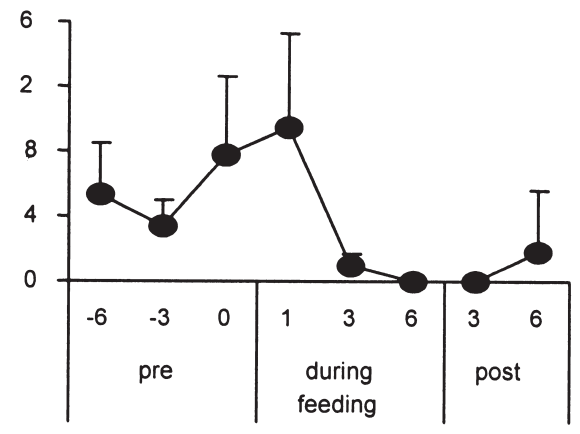

B. Ruminococcus, $\mu \mathrm{g} / \mathrm{ml}$

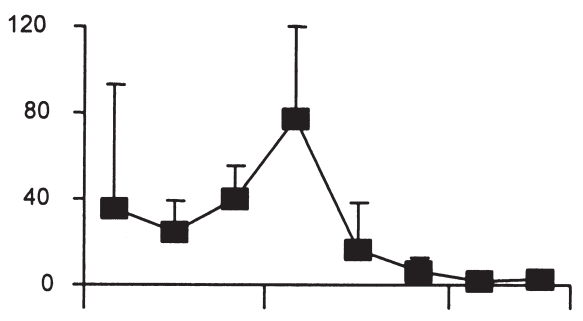

Figure 1. Concentrations of Fibrobacter (A), Ruminococcus (B), and Chytridiomycetes (C) and xylanase activity (D) in rumen of goats fed methanol extract of Sapindus rarak at pre, during and post feeding

The negative effect on fungi may be similar to that on protozoa as they both are grouped as eukaryotes which have membrane sterol. It was postulated that saponins bind with the membrane sterol and depress protozoa (Wallace et al., 2002).

When the fibrolytic microbes reduced even at post feeding, one expected that the fibrolytic enzymes would also reduce. But in this study, the enzyme reduced only during MS feeding but regained their activities soon at post feeding. It clearly shows that saponins in MS gave a negative effect to some extent to both fibrolytic microbes and enzymes. But a quick regain of fibrolytic activity at post feeding must be contributed by activities of other bacteria and protozoa. Protozoa excrete several fibrolytic enzymes, therefore, it is one of the major determinants on the level of fibrolytic enzyme activity in the rumen ecosystem (William and Withers, 1991) and also some bacteroides, Butyrivibrio fibriosolvens and Eubacterium cellulosolvens produce fibrolytic enzymes (Chesson and Forsberg, 1988). Further evaluation is followed to investigate the effect of saponins containing 
methanol extract of Sapindus rarak on whole tract digestibility and performance of animals.

\section{CONCLUSIONS}

There was no correlation between fibrolytic microbes concentration and xylanase or CMCase activities in goat fed saponins containing methanol extract of Sapindus rarak.

\section{REFERENCES}

Chesson A., Forsberg C.W., 1988. Polysaccharide degradation by rumen microorganisms. In: P.N. Hobson (Editor). The Rumen Microbial Ecosystem. Elsevier Applied Science, London and New York, pp. 251-284

Hess H.D., Kreuzer M., Diaz T.E., Lascano C.E., Carulla J.E., Soliva C.R., Machmüller A., 2004. Saponin rich tropical fruit affect fermentation and methanogenesis in faunated and defaunated rumen fluid. Anim. Feed Sci. Tech. 109, 79-94

Muetzel S., Hoffmann E.M., Becker K., 2003. Supplementation of barley straw with Sesbania pachcarpa leaves in vitro: effects on fermentation variables and rumen mircobial concentration structure quantified by ribosomal RNA-targeted probes. Brit. J. Nutr. 89, 445-453

Thalib A., Widiawati Y., Hamid H., Suherman D., Sabrani M., 1997. The effects of saponin from Sapindus rarak fruit on rumen microbes and performance of sheep. J. Ilmu Ternak dan Vet. 2, $17-21$

Wallace R.J., Mcewan N.R., Mcinntosh F.M., Teferedegne B., Newbold C.J., 2002. Natural products as manipulators of rumen fermentation. Asian-Austr. J. Anim. Sci. 15, 1458-1468

Wang Y., McAllister T.A., Yanke L.J., Xu Z.J., Cheeke P.R., Cheng K.J., 2000. In vitro effects of steroidal saponins from Yucca schidigera extract on rumen microbial protein synthesis and ruminal fermentation. J. Sci. Food Agr. 80, 2114-2122

Wina E., Muetzel S., Hoffmann E., Makkar H.P.S., Becker K., 2004. The effect of secondary compounds in forages on the rumen microorganisms quantified by $16 \mathrm{~S}$ and $18 \mathrm{~S}$ rRNA. In: Proceedings of FAO/IAEA International Symposium on Applications of Gene-Based Technologies for Improving Animal Production and Health in Developing Countries (in press)

Williams A.G., Withers S.E., 1991. Effect of ciliate protozoa on the activity of polysaccharidedegrading enzymes and fibre breakdown in the rumen ecosystem. J. Appl. Bacteriol. 70, 144-155 